\title{
Corrigendum to "Biodegradation of polyester polyurethane during commercial composting and analysis of associated fungal communities" [Bioresour. Technol. 158 (2014) 374-377]
}

Urooj Zafar $^{\mathrm{a}}$, Petrus Nzerem ${ }^{\mathrm{b}}$, Adrian Langarica-Fuentes ${ }^{\mathrm{a}}$, Ashley Houlden ${ }^{\mathrm{a}}$, Alan Heyworth ${ }^{\mathrm{c}}$, Alberto Saiani ${ }^{\mathrm{d}}$, Geoff D. Robson ${ }^{\mathrm{a}, *}$

${ }^{\text {a }}$ Faculty of Life Sciences, Michael Smith Building, University of Manchester, Manchester M13 9PT, UK

${ }^{\mathrm{b}}$ School of Chemical Engineering and Analytical Science, Faculty of Engineering and Physical Sciences, University of Manchester, Manchester M60 1QD, UK

${ }^{\mathrm{c}}$ The TEG Group PLC, Westmarch House, 42 Eaton Avenue, Chorley PR7 7NA, UK

${ }^{\mathrm{d}}$ School of Materials, Faculty of Engineering and Physical Sciences, University of Manchester, Manchester M13 9PL, UK

The authors regret to inform that the name of the second author was misspelt in the article. Please read the name as Petrus Nzerem instead of
Petrus Nzeram. The corrected author name is shown above. The authors would like to apologise for any inconvenience caused.

DOI of original article: https://doi.org/10.1016/j.biortech.2014.02.077

* Corresponding author. 